\title{
Sialodacryoadenitis Virus Infection, Rat
}

Robert O. Jacoby

Synonym. Rat coronavirus infection

\section{Gross Appearance}

Lesions develop during the first week after infection and occur primarily in the submandibular and parotid salivary glands, which are located on the anteroventral and anterolateral aspects of the neck, respectively (Fig. 215). Affected glands are unilaterally or bilaterally enlarged and pale yellow to white in contrast to their normal tan color (Fig. 216). Periglandular connective tissue is often edematous and, together with glandular enlargement, may cause clinically detectable cervical swelling. The cervical lymph nodes may also be enlarged and edematous. They are frequently congested, especially early in infection, and occasionally flecked with red spots.

\section{Microscopic Features}

The glandular lesions of sialodacryoadenitis (SDA) consist of necrosis and inflammation during acute disease and squamous metaplasia as tissues are repaired (Jonas et al. 1969; Jacoby et al. 1975). Serous and mixed salivary glands in the oropharynx and neck are affected, but mucous salivary glands are resistant. Infection begins as rhinotracheitis. Earliest glandular lesions are detected in the submandibular salivary glands, where necrosis of ductular epithelium can begin by 4 days postinfection (Fig. 217) and is associated with intracytoplasmic viral antigen. Infection and necrosis of adjacent acinar parenchyma begins shortly thereafter and quickly involves large areas of the parenchyma (Fig. 218). Necrosis is accompanied by inflammatory edema, which also engulfs periglandular connective tissues. The inflammatory cells consist of small and large mononuclear cells and polymorphonuclear leukocytes. Necrosis and inflammation in the parotid and oropharyngeal salivary glands develop in a similar pattern. The sublingual salivary glands, which are mucin-secreting glands at the anterior pole of the submandibular glands
(Greene 1959), are not affected (Fig. 219). Cervical lymph nodes are congested during the first 4-5 days of infection, but remain enlarged from ensuing hyperplasia. By the end of the first week, active germinal centers appear in the cortex and medullary cords begin to fill with plasma cells. Mild focal necrosis and focal hemorrhage may occur during this period.

Repair begins during the second week of infection and is normally complete by the end of the third week. It proceeds efficiently because acinar and ductular basement membrane remain intact through acute infection. The characteristic sign of repair is squamous metaplasia of ductular epithelium (Figs. 219, 220), a transient lesion that is replaced by normal columnar epithelium. Acinar regeneration entails the maturation of clusters or rosettes of small hyperchromatic cells into normal acini. Inflammation and edema subside coincidently with reconstitution of glandular parenchyma, but interstitial foci of nonsuppurative inflammation may linger after parenchymal repair is complete. Fibrosis is not a significant sequel of SDA, but small interstitial scars may develop.

\section{Ultrastructure}

The ultrastructure of SDA infection has not been thoroughly described. Jonas and coworkers (1969) found two types of viral particles in ductal epithelium of submaxillary glands of experimentally infected rats. One type was $60-70 \mathrm{~nm}$ in diameter and had an electron-dense core. The second type was about $10-20 \mathrm{~nm}$ in diameter and occurred as cytoplasmic aggregates. Two types of cytoplasmic vacuoles also were observed. One had an electronlucent matrix, was membrane bound, and contained cytoplasmic debris, membrane fragments, and cell organelles. The other also was membrane bound and contained the electron-dense viral particles. Parker and coworkers (1970) described rat coronavirus as a pleomorphic virus $60-200 \mathrm{~nm}$ in diameter. The variation in reported measurements appears to be due to differences in the preparations used. 


\section{Differential Diagnosis}

Sialoadenitis in the rat is characteristic of rat coronavirus infection. Two isolates were described in the early 1970s; SDA virus (Bhatt et al. 1972), rat coronavirus (Parker et al. 1970), and others have since been added (Jacoby 1986). The various isolates have comparable pathogenicity for rats and thus far cannot be distinguished serologically. Cytomegalovirus infection in the salivary glands of rats is associated with enlarged ductal epithelial cells which may contain intranuclear inclusions (Lyon et al. 1959). An unclassified cytopathic agent has been isolated from the submaxillary salivary glands of rats, but it is apparently nonpathogenic (Ashe 1969). Salivary gland tumors are rare in rats, and no other classes of microbial agents have been consistently associated with sialoadenitis. It is worth noting that rat

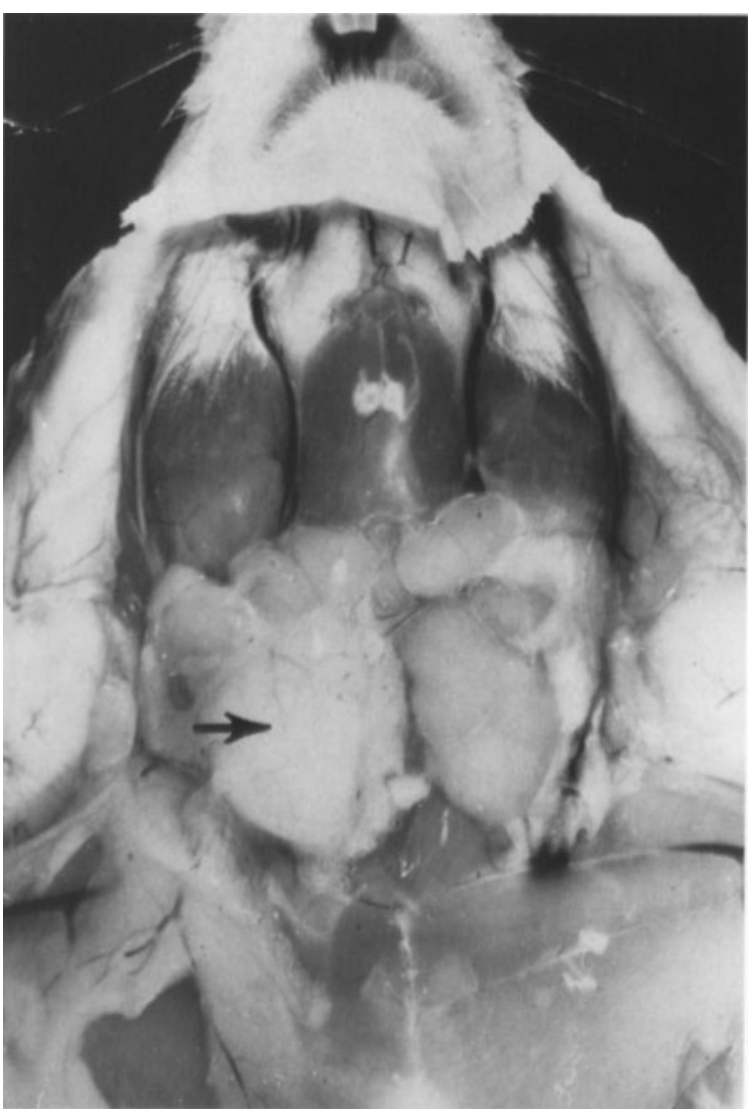

Fig. 215. Gross anatomy, ventral aspect of the neck, rat. (Adapted from Greene 1959, with permission of Hafner Publ. Co.)

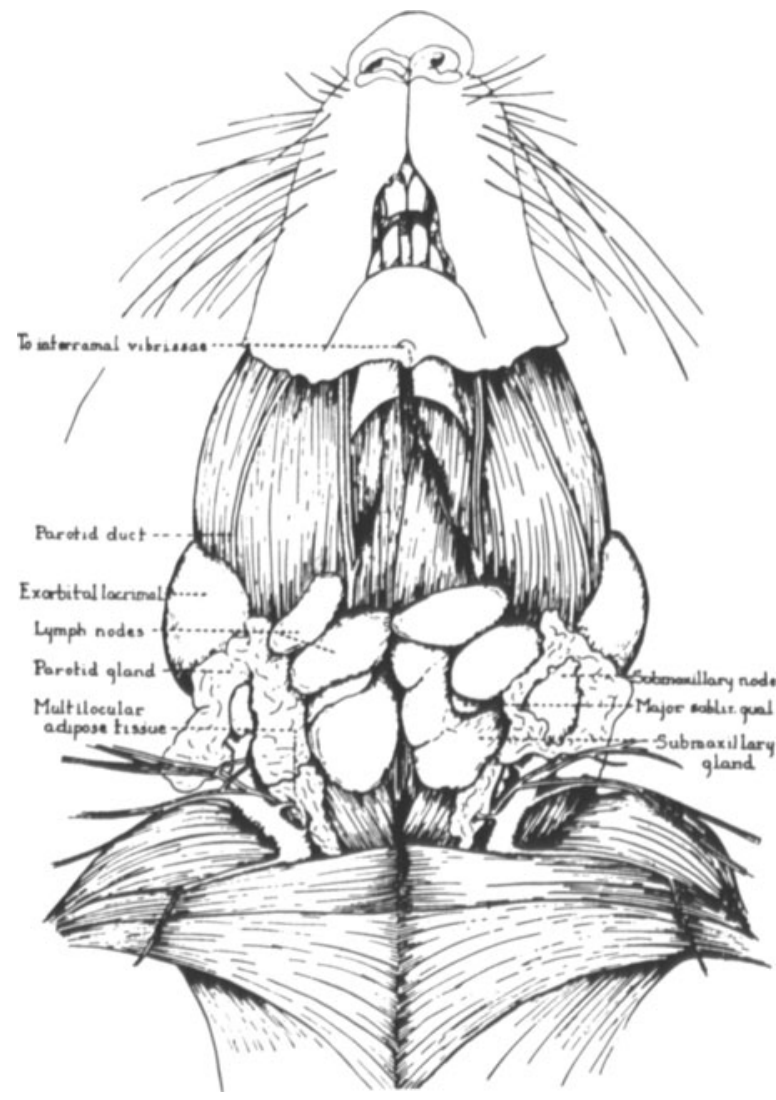

Fig. 216. Submaxillary gland (arrow), rat inoculated intranasally with sialodacryoadenitis virus 5 days previously. The gland is swollen and pale. Cervical lymph nodes are also enlarged. (From Jacoby et al. 1979, with permission of Academic Press)

Fig. 217. (upper left) Submaxillary salivary gland, rat, 4 days after intranasal inoculation of sialodacryoadenitis virus. Note necrosis of a large salivary duct and mild interstitial inflammation. Early signs of degeneration in adjacent acini are indicated by intracytoplasmic vacuoles. (From Jacoby et al. 1975, with permission of Veterinary Pathology.) H\&E, $\times 400$

Fig. 218. (lower left) Submaxillary gland, rat infected intranasally with sialodacryoadenitis virus 5 days previously. Note widespread necrosis and inflammation. (From Jacoby et al. 1975, with permission of Veterinary Pathology.) H\&E, $\times 160$

Fig. 219. (upper right) Submaxillary gland, rat, effaced by severe sialoadenitis 6 days after infection with sialodacryoadenitis virus. Squamous metaplasia is evident in a salivary duct. The adjacent sublingual gland is normal. (From Jacoby et al. 1975, with permission of Veterinary Pathology.) H\&E, $\times 160$

Fig. 220. (lower right) Submaxillary gland, rat inoculated with sialodacryoadenitis virus 9 days previously. Note the prominent squamous metaplasia of ductal epithelium and clusters of regenerating acini, especially in the lower right quadrant. (From Jacoby et al. 1975, with permission of Veterinary Pathology.) $\mathrm{H} \& \mathrm{E}, \times 160$ 


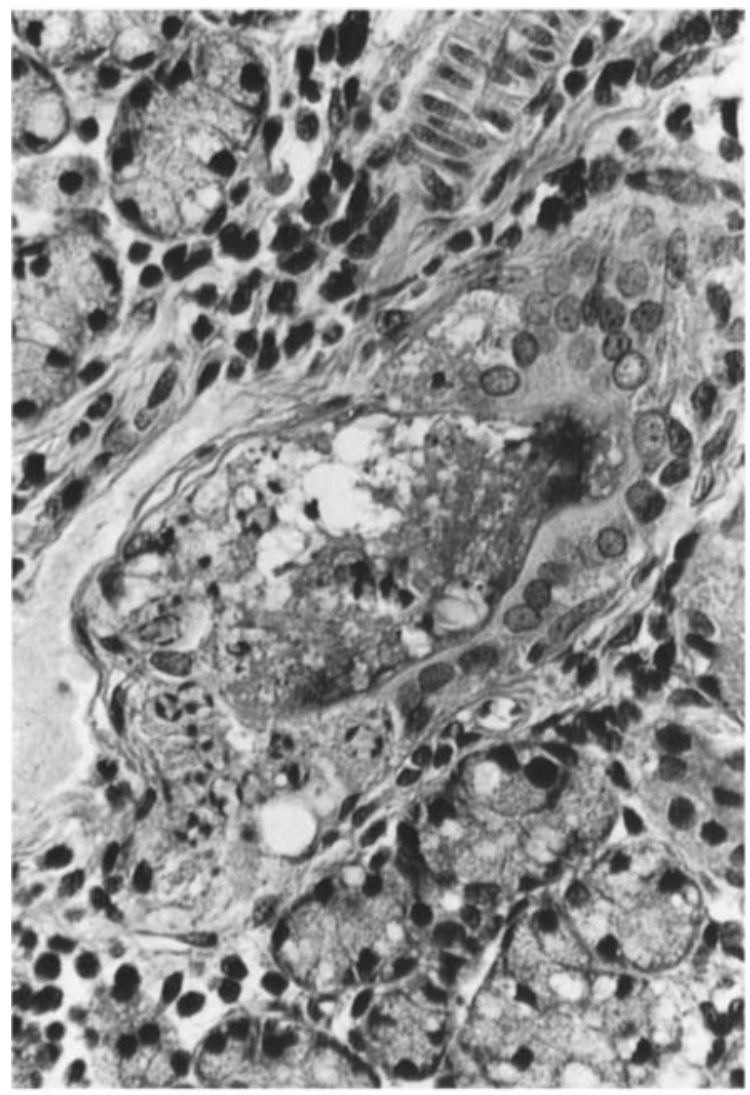

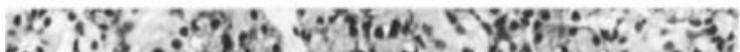

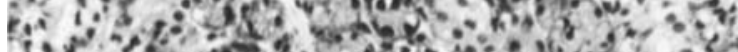

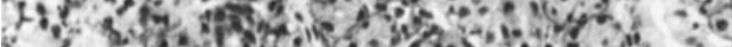

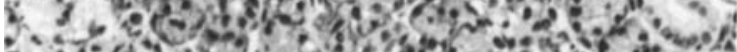

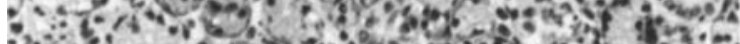

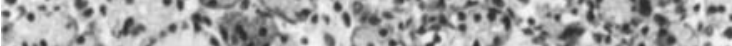

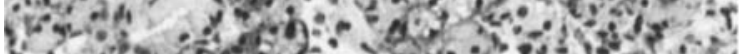

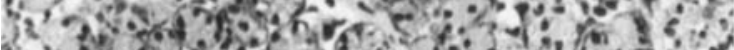

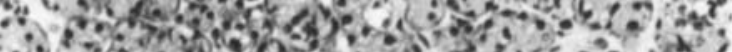

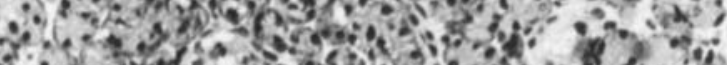

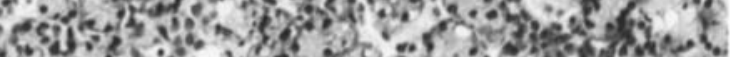

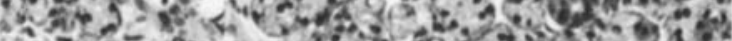

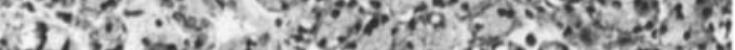

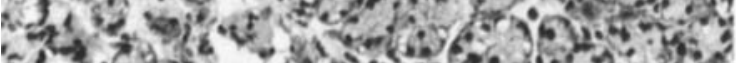

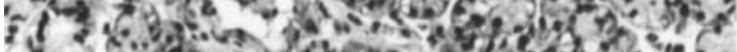

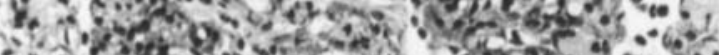

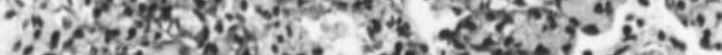

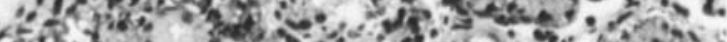

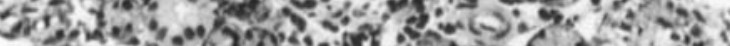

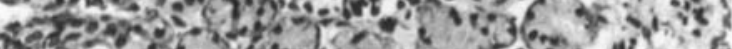

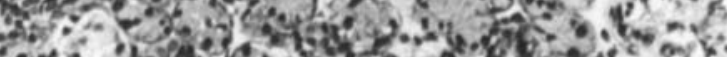

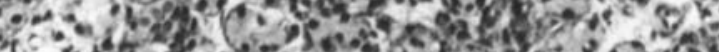

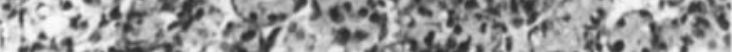

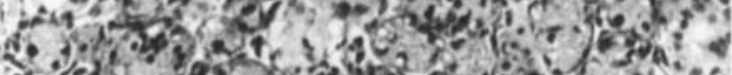

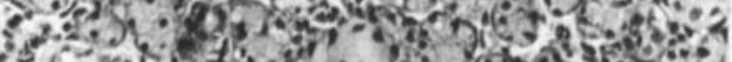

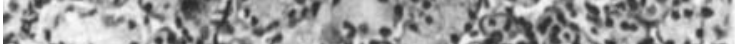

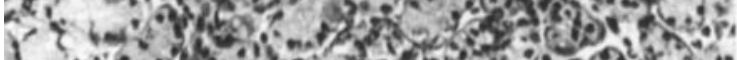

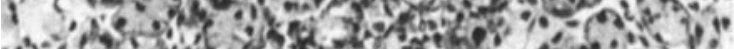

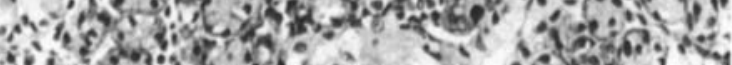

S.".

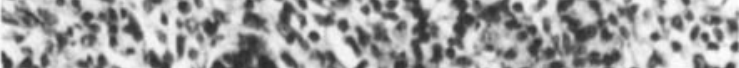
1.2. sos.

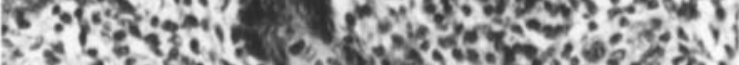
*2.

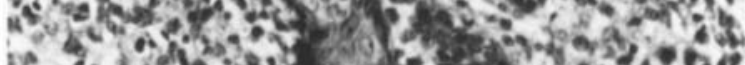

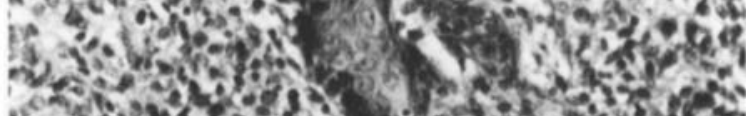

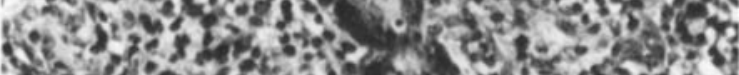

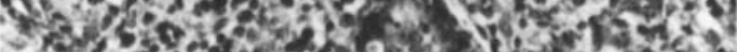

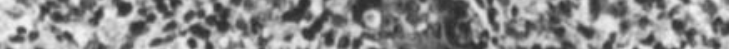

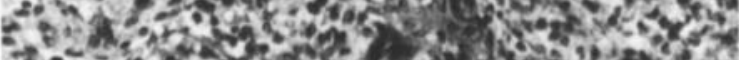

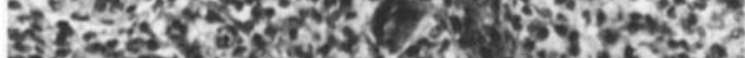

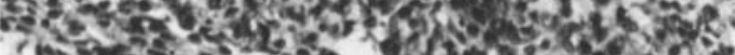

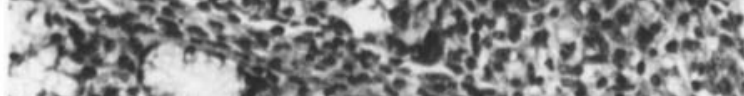
3.

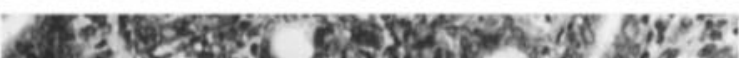

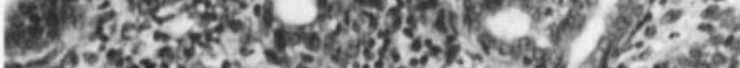

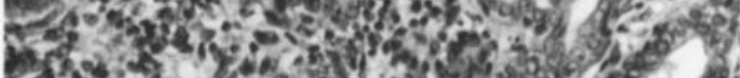

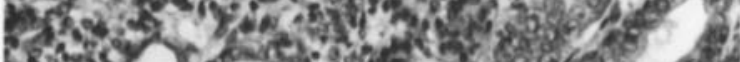

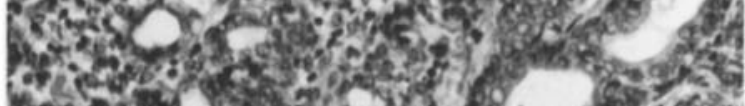
W.

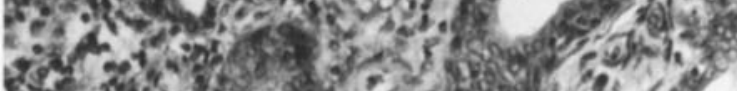

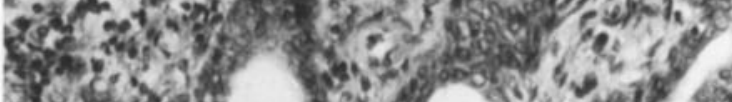

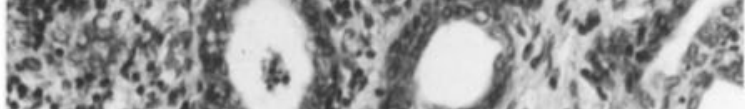
B.

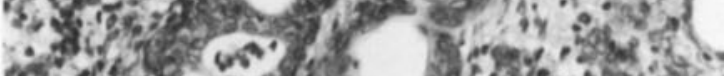

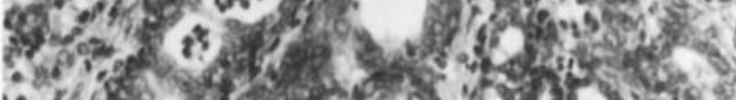

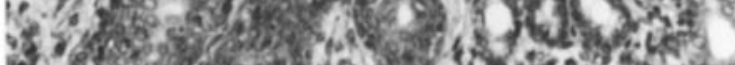

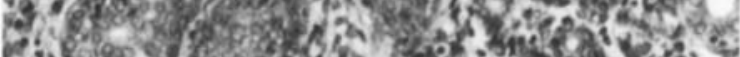

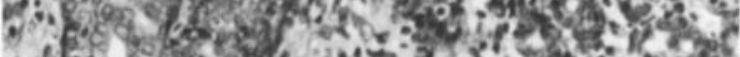

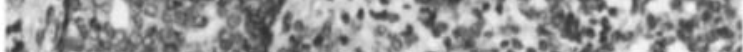
A.

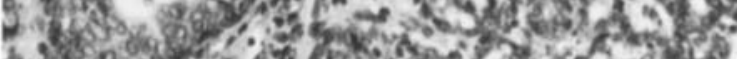

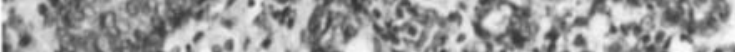

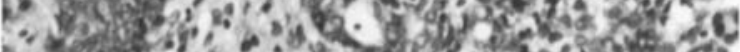
Nove

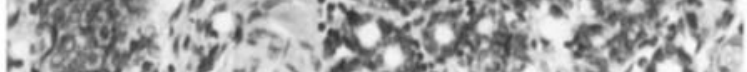

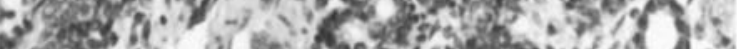

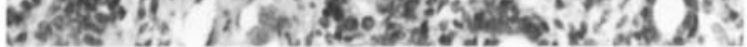


coronaviruses are antigenically related to mouse coronaviruses commonly grouped under the name mouse hepatitis virus (MHV) (Bhatt et al. 1972; Parker et al. 1970). Because under experimental conditions SDA virus can infect mice (Bhatt et al. 1977) and MHV can infect rats (Taguchi et al. 1979), some caution in serologic techniques and interpretation is advised when investigating coronavirus infections in these species, especially when they are housed near one another (Jacoby et al. 1979).

\section{Biologic Features}

SDA is a common infectious disease of rats. It is acute and self-limiting and can affect rats at any age. It usually occurs, however, in weanlings that have recently lost maternal immunity or in sucklings of nonimmune dams. Morbidity is high, but mortality is low. Clinical disease develops by 1 week after exposure to the virus and is characterized by one or more of the following signs: sneezing; photophobia; lacrimation, including excessive secretion of porphyrin pigment (so-called chromodacryorrhea), which imparts a red stain to periocular and perinasal skin; cervical swelling due to palpably enlarged submaxillary salivary glands and edema; transient anorexia and weight loss; and reduced breeding performance. The severity of clinical disease can vary among rat strains, and mild disease may be asymptomatic (Bhatt and Jacoby 1985). Seroconversion, which typically occurs about 1 week after exposure to virus, marks the cessation of infection and transmission and the initiation of repair. Although immunity to systemic infection is long-lived, seropositive rats can be transiently reinfected and transmit virus to naive rats for several days (Percy et al. 1990; Weir et al. 1990b).

Convalescence is associated with humoral immunity, which can be detected serologically by neutralization (Bhatt et al. 1972), immunofluorescence (Smith 1983), or enzyme-linked immunoabsorption (Peters and Collins 1981). Infection of athymic rats, by contrast, is persistent and results in chronic active inflammation and prominent scarring of the salivary glands. Affected rats also transmit infection for prolonged periods and may develop a wasted appearance (Weir et al. 1990a). SDA has been detected in laboratory rats in North America, Europe, and
Asia and is probably one of the most common infections of laboratory rats worldwide. The infection is difficult to eliminate until susceptible animals have become immune or until rooms with infected rats have been depopulated. Virus is spread rapidly by contact or aerosol and infects the respiratory tract before reaching the salivary glands and lacrimal glands. The route of spread from the nasopharynx has not been confirmed, but might involve retrograde infection of salivary and lacrimal excretory ducts. Viremia, if it occurs, is likely to be transient (Jacoby et al. 1975). Virus spread in immunocompetent rats is limited to the respiratory tract, salivary glands, lacrimal glands, and regional lymph nodes. Infection of the urinary tract has been demonstrated, however, in athymic rats (Weir et al. 1990a). Keratoconjunctivitis associated with infection has been attributed to corneal dehydration from interrupted tear production rather than to viral invasion of the cornea (Lai et al. 1976).

As previously stated, SDA virus is closely related to a coronavirus isolated from rats by Parker and coworkers (Parker et al. 1970; Bhatt and Jacoby 1977). SDA virus is relatively large $(60-200 \mathrm{~nm})$ and pleomorphic and can be grown in monolayer cultures of primary rat kidney (Bhatt et al. 1972) or in mouse L2 fibroblasts (Percy et al. 1989; Gaertner et al. 1991). The cytopathic effect of rat coronaviruses is syncytia formation. Infection is typically detected serologically by enzymelinked immunosorbent assay (ELISA) or immunofluorescence assay.

SDA may affect the results in research using rats (Barthold 1985). The most significant interference stems from chronic ophthalmologic lesions secondary to dacryoadenitis, which are described elsewhere in these monographs. During acute disease, rats may consume less food and have transient weight loss and reduced breeding performance (Utsumi et al. 1980). Infected rats may also be at greater risk during general anesthesia, especially if they are restrained with head and neck extended. Nasal exudates from acute rhinitis (see p. 249), and swelling of cervical tissues may combine to narrow or obstruct the upper airways. Biochemical or morphological studies on affected glands would not be suitable during acute infection or convalescence (Percy et al. 1988). Whether squamous metaplasia of healing glands can affect the course of carcinogenicity studies has not been clarified. There is no published evidence, how- 
ever, that such lesions increase the prevalence of salivary tumors in rats treated with potential or known carcinogens.

\section{Comparison with Other Species}

The lesions of SDA in rats are not duplicated in natural disease of other laboratory or domestic animal species. Sialoadenitis in humans may be infectious (e.g., mumps) or noninfectious (Vickers and Gorling 1977), but the pathogenesis, distribution of lesions, and other manifestations of human sialoadenitis do not closely resemble SDA.

\section{References}

Ashe WK (1969) Properties of the rat submaxillary gland virus hemagglutinin and antihemagglutinin and their incidence in apparently healthy gnotobiotic and conventional rats. J Gen Virol 4:1-7

Barthold SW (1985) Research complications and state of knowledge of rodent coronavirus. In: Hamm TA (ed) Complications of viral and mycoplasmal infections in rodents to toxicology research and testing. Hemisphere, Washington DC

Bhatt PN, Jacoby RO (1977) Experimental infection of adult axenic rats with Parker's rat coronavirus. Arch Virol 54:345352

Bhatt PN, Jacoby RO (1985) Epizootiological observations of natural and experimental infection with sialodacryoadenitis virus in rats. Lab Anim Sci 35:129-134

Bhatt PN, Percy DH, Jonas AM (1972) Characterization of the virus of sialodacryoadenitis of rats: a member of the coronavirus group. J Infect Dis 126:123-130

Bhatt PN, Jacoby RO, Jonas AM (1977) Respiratory infection in mice with sialodacryoadenitis virus, a coronavirus of rats. Infect Immun 18:823-827

Gaertner DJ, Smith AL, Paturzo FX, Jacoby RO (1991) Susceptibility of rodent cell lines to rat coronaviruses and differential enhancement by trypsin or DEAE-dextran. Arch Virol 118:57-66

Greene EC (1959) Anatomy of the rat. Hafner, New York, p 93 (Transactions of American Philosophical Society, vol 27)

Jacoby RO (1986) Rat coronavirus. In: Bhatt PN, Jacoby RO, Morse HC, New AE (eds) Viral and mycoplasmal infections of laboratory rodents: effects on biomedical research. Academic, Orlando, pp 625-638
Jacoby RO, Bhatt PN, Jonas AM (1975) Pathogenesis of sialodacryoadenitis in gnotobiotic rats. Vet Pathol 12:196209

Jacoby RO, Bhatt PN, Jonas AM (1979) Viral disease. In: Baker H, Lindsey JR, Weisbroth SH (eds) The laboratory rat, vol 1: biology and diseases. Academic, New York, chap 11

Jonas AM, Craft J, Black L, Bhatt PN, Hilding D (1969) Sialodacryoadenitis in the rat. A light and electron microscopic study. Arch Pathol 88:613-622

Lai YL, Jacoby RO, Bhatt PN, Jonas AM (1976) Keratoconjunctivitis associated with sialodacryoadenitis in rats. Invest Ophthalmol 15:538-541

Lyon HW, Christian JJ, Miller CW (1959) Cytomegalic inclusion disease of lacrimal glands in male laboratory rats. Proc Soc Exp Biol Med 101:164-166

Parker JC, Cross SS, Rowe WP (1970) Rat coronavirus (RCV): a prevalent, naturally occurring pneumotropic virus of rats. Arch Gesamte Virusforsch 31:293-302

Percy DH, Hayes MA, Kocal TE, Wojcinski ZW (1988) Depletion of salivary gland epidermal growth factor by sialodacryoadenitis virus infection in the Wistar rat. Vet Pathol 25:183-192

Percy DH, Bond S, MacInnes J (1989) Replication of sialodacryoadenitis virus in mouse L-2 cells. Arch Virol 104:323-333

Percy DH, Bond SJ, Paturzo FX, Bhatt PN (1990) Duration of protection from reinfection following exposure to sialodacryoadenitis virus in Wistar rats. Lab Anim Sci 40:144-149

Peters RL, Collins MJ Jr (1981) Use of mouse hepatitis virus antigen in an enzyme-linked immunosorbent assay for rat coronaviruses. Lab Anim Sci 31:472-475

Smith AL (1983) An immunofluorescence test for detection of serum antibody to rodent coronaviruses. Lab Anim Sci 33:157-160

Taguchi F, Yamada A, Fujiwara K (1979) Asymptomatic infection of mouse hepatitis virus in the rat. Arch Virol 59:275279

Utsumi K, Ishikawa T, Maeda T, Shimizu S, Tatsumi H, Fujiwara K (1980) Infectious sialodacryoadenitis and rat breeding. Lab Anim 14:303-307

Vickers RA, Gorlin RJ (1977) Face, lips, teeth, mouth, jaws, salivary glands and neck. In: Anderson WAD, Kissane JM (eds) Pathology, 7th edn, vol 2. Mosby, St Louis, chap 29

Weir EC, Jacoby RO, Paturzo FX, Johnson EA, Ardito RB (1990a) Persistence of sialodacryoadenitis virus in athymic rats. Lab Anim Sci 40:138-143

Weir EC, Jacoby RO, Paturzo, FX, Johnson EA (1990b) Infection of SDAV-immune rats with SDAV and rat coronavirus. Lab Anim Sci 40:363-366 